$P P B=$

\title{
Nota Científica \\ Determinação da umidade da madeira em tora por diferentes métodos
}

Danilo Barros Donato ${ }^{1}$, Renato Vinícius Oliveira Castro ${ }^{2}$, Angélica de Cássia Oliveira Carneiro ${ }^{1}$, Ana Márcia Ladeira Macedo Carvalho ${ }^{1}$, Bárbara Luísa Corradi Pereira ${ }^{3}$, Aylson Costa Oliveira ${ }^{3}$, Conrad Julião Barbosa ${ }^{4}$

\author{
${ }^{1} U$ niversidade Federal de Viçosa, Departamento de Engenharia Florestal, CEP 36.570-000, Viçosa, MG, Brasil \\ ${ }^{2}$ Universidade Federal de São João Del-Rei, Departamento de Ciências Agrárias, CP 56, Campus Sete Lagoas, Rod. MG 424 Km, CEP $35.701-970$, \\ Sete Lagoas, MG, Brasil \\ ${ }^{3}$ Universidade Federal de Mato Grosso, Faculdade de Engenharia Florestal, Boa Esperança, CEP 78.060-900, Cuiabá, MT, Brasil \\ ${ }^{4}$ Gerdau Florestal S.A, Fazenda Cabana Santa Bárbara, CEP 39.205-000, Três Marias, MG, Brasil
}

\section{*Autor correspondente: \\ danilobarros20@hotmail.com \\ Termos para indexação: \\ Métodos alternativos \\ Teor de umidade \\ Eucalipto \\ Regressão}

Index terms:

Alternative methods

Moisture content

Eucalyptus

Regression

\section{Histórico do artigo:}

Recebido em 04/11/2013

Aprovado em 02/12/2014

Publicado em 31/12/2014

doi: 10.4336/2014.pfb.34.80.608

\begin{abstract}
Resumo - O objetivo deste trabalho foi comparar três métodos alternativos de determinação do teor de umidade da madeira em tora com o método preconizado pela ABNT. O teor de umidade da madeira foi determinado em uma amostra de serragem e com um medidor elétrico capacitivo. Além disso, o teor de umidade foi determinado pelo método da ABNT em amostras de madeira. Concluiu-se, portanto, que é viável a utilização de métodos alternativos para a determinação da umidade da madeira em toras, em substituição ao método tradicional, desde que se façam ajustes.
\end{abstract}

\section{Determination of wood logs moisture by different methods}

\begin{abstract}
The aim of this study was to compare three alternative methods to determine the moisture content of wood logs with the method recommended by ABNT. The moisture content of the wood was determined in a sawdust sample and with a electric meter capacitive. It was also determined the moisture content of a disk sample using the method recommended by ABNT. Using the regression model, all the methods were statistically similar. It was concluded that the use of alternative methods for determining the moisture content of wood in logs is feasible, to substitute the traditional method, but corrections must be implemented.
\end{abstract}

A umidade da madeira é uma característica física que exerce grande influência sobre sua trabalhabilidade e utilização nos diversos fins, principalmente para o processo de carbonização (Barrichelo \& Brito, 1977). O processo de carbonização da madeira é um exemplo onde a utilização da matéria prima com o elevado teor de umidade pode causar inúmeros problemas, aumentando o tempo de carbonização, reduzindo o rendimento gravimétrico em carvão vegetal, além de afetar sua qualidade (Rezende, 2009). O controle da umidade da madeira mostra-se, portanto, de extrema importância para se obter um produto final com características desejáveis, e entender como a água encontra-se na madeira, estudar sua influência nas propriedades físicas e elétricas do material estão intimamente ligados à correta determinação do teor de (Batista et al., 2011).

A determinação da umidade da madeira deve ser realizada desde a colheita até a sua utilização, uma vez que as propriedades da madeira variam de acordo com a quantidade de água presente em seu interior. Para o acompanhamento dos teores de umidade da madeira, faz-se necessário o desenvolvimento e aprimoramento de metodologias de determinação rápida, de baixo custo e precisas. 
Atualmente, informações relativas da distribuição da umidade no interior da madeira são dadas de acordo com a norma estabelecida pela ABNT NBR 14929, podendo ser denominado de método tradicional. A determinação do teor de umidade por este método é feita através da diferença de massa de amostras, antes e depois de passarem por um processo de secagem em estufa a $103 \pm$ $2^{\circ} \mathrm{C}$ até peso constante (Associação Brasileira de Normas Técnicas, 2003). Porém, é um procedimento demorado, com dificuldades operacionais.

Existem diversos métodos alternativos para determinar o teor de umidade da madeira. Medidores elétricos com princípios resistivos e capacitivos proporcionam resposta imediata e de baixo custo, entretanto com exatidão contestada. Por outro lado, utilização de microondas para determinação da umidade da madeira, é uma alternativa bastante viável, em termos práticos, por proporcionar uma resposta rápida, mas é de elevado custo e ainda pouco desenvolvido (Calonego et al., 2006).

Em comparação ao método da ABNT, o método dos medidores elétricos apresenta vantagens com relação à praticidade e rapidez, porém esses aparelhos não foram desenvolvidos para determinar o teor de umidade da madeira em tora.

Outro método alternativo que vem sendo utilizado por algumas empresas do setor de produção de carvão vegetal para determinação da umidade em toras de eucalipto, em substituição ao método tradicional, consiste em utilizar a serragem obtida através de uma furadeira elétrica, sendo posteriormente seca em estufa ou em balança determinadora de umidade até peso constante. Porém, não há estudos na literatura a respeito deste método.

Para ambos os métodos (medidores elétricos e serragem) é necessário desenvolver-se curvas de correção para compará-los ao método tradicional.

Assim, de modo a contribuir com o setor florestal brasileiro, o presente trabalho objetivou avaliar três métodos alternativos para determinação da umidade da madeira de eucalipto em tora, correlacionando estes resultados com os obtidos pelo método tradicional. $\mathrm{O}$ estudo também buscou determinar um fator de correção e um modelo de regressão para corrigir eventuais distorções entre os resultados encontrados pelos métodos alternativos em comparação com o método tradicional.

Foram avaliadas 54 toras de $3 \mathrm{~m}$ de comprimento do gênero Eucalyptus sp., aos seis anos de idade. As toras foram provenientes de um plantio, instalado em espaçamento 3,0 $\mathrm{m}$ x 2,0 m, pertencente a uma empresa do setor florestal, localizada no Município de TrêsMarias, MG.

O experimento foi conduzido no pátio da empresa, sendo avaliadas três alternativas para determinação do teor de umidade da tora em comparação com o método estabelecido pela norma ABNT NBR 14929 (Associação Brasileira de Normas Técnicas, 2003). Das alternativas testadas nesse estudo, duas foram com o uso de um medidor elétrico capacitivo, sendo que em uma delas a leitura para determinação do teor de umidade foi realizada a $25 \mathrm{~cm}$ da extremidade da tora e a outra leitura foi realizada no sentido lateral da tora (transversal).

Para a determinação do teor de umidade pelo medidor elétrico capacitivo, primeiramente foi selecionado no aparelho o grupo da madeira a ser medida com o código da espécie e sua correspondente numeração. Logo em seguida, foram feitas as leituras do teor de umidade no sentido do topo da tora, a $25 \mathrm{~cm}$ da sua extremidade. O mesmo procedimento foi realizado para determinação do teor de umidade no sentido lateral da tora.

Alguns cuidados foram adotados para a obtenção de melhores resultados, como por exemplo, foram evitadas superfícies rachadas ou molhadas.

Já a terceira alternativa de determinação do teor de umidade da tora foi com o uso de uma furadeira elétrica, onde foram retiradas amostras na forma de serragem da tora a $25 \mathrm{~cm}$ de sua extremidade, fazendo-se um furo até que a broca da furadeira atravessasse todo diâmetro da tora, a fim de homogeneizar a amostra. Neste tratamento foi evitada a retirada de serragem em áreas cuja madeira apresentasse algum defeito. A serragem, imediatamente após ser retirada das toras, foi pesada em balança de precisão de $0,01 \mathrm{~g}$ para que não perdesse umidade para o ambiente e, em seguida, levada à estufa a $103 \pm 2{ }^{\circ} \mathrm{C}$ por 12 horas. Com base na massa inicial (úmida) e final (seca em estufa) de cada amostra em forma de serragem, determinou-se a umidade da tora (Equação 1):

$\mathrm{U} \%_{\mathrm{BS}}=(\mathrm{MU}-\mathrm{MS}) / \mathrm{MS} * 100$

Em que: $U \%_{B S}=$ percentagem de umidade em base seca; $\mathrm{MU}=$ massa úmida da amostra; $\mathrm{MS}$ = massa seca da amostra .

Para a determinação do teor de umidade pelo método da ABNT (Associação Brasileira de Normas Técnicas, 2003) foram retirados discos de aproximadamente 7 $\mathrm{cm}$ de espessura a $25 \mathrm{~cm}$ da extremidade de cada tora. Posteriormente, esses discos foram pesados, visando à determinação da massa úmida (MU), e secos em estufa a $103 \pm 2{ }^{\circ} \mathrm{C}$ até peso constante, para obtenção da sua 
massa seca (MS). Após a sua secagem foi determinado o seu teor de umidade na base seca da madeira, de acordo com a norma estabelecida pela norma ABNT NBR 14929 através da Equação 1.

Os valores do teor de umidade obtidos por cada um dos métodos alternativos utilizados nesse estudo foram comparados com os valores obtidos pela metodologia da ABNT pelo teste $t$ para amostras dependentes, a 95\% de probabilidade, com auxílio do software Statistica 8.0 (Statsoft, 2009).

Foi estabelecido um fator de correção para os métodos alternativos utilizado nesse estudo de acordo com a Equação 2:

Fator de correção $\mathrm{j}=\frac{\sum_{\mathrm{j}=1}^{\mathrm{n}}\left(\text { Umidade }_{\mathrm{ABNT}} / \mathrm{U}_{\text {midade alternativa }}{ }_{\mathrm{ij}}\right)}{\mathrm{n}}$

Em que: Fator de correção $j$ é utilizada para o método alternativo $j$; Umidade $\mathrm{ABNT}_{i}$ é a umidade da tora $i$ obtida pelo método da ABNT; $n$ é o número de toras amostradas; Umidade alternativa $a_{i j}$ é a umidade da tora $i$ obtida pelo método alternativo $j$.

A umidade corrigida de cada tora $i$ foi estimada pela multiplicação da umidade obtida pelo método alternativo $j$ multiplicado pelo seu fator de correção.

Foi utilizado também um modelo de regressão para fazer correções dos valores do teor de umidade obtidos pelos métodos alternativos em relação à umidade real. O modelo de regressão utilizado teve como variável dependente o teor de umidade real da madeira (umidade obtida pelo método tradicional) e como variáveis independentes, o diâmetro das toras e o valor da umidade obtida pelo método alternativo $j$. O modelo matemático utilizado é mostrado na Equação 3:

Umidade real $=\beta_{0}+\beta_{1}+\beta_{2}{ }^{*}$ Umidade $_{\mathrm{i}}+\varepsilon$

Em que: $\beta_{0}, \beta_{1}, \beta_{2}$ são os parâmetros do modelo; $\varepsilon$ é o erro aleatório.

A umidade corrigida de cada tora foi estimada pela aplicação da equação ajustada.

A leitura direta dos três métodos adotados diferiu significativamente do método da ABNT (Tabela 1). Quando utilizado o fator de correção, o método da amostra de madeira em forma de serragem não apresentou diferença significativa quando comparado ao método da ABNT. Com a aplicação do modelo de regressão, todos os métodos utilizados não apresentaram diferença significativa quando comparado ao tradicional.
O método que mais se aproximou do método da ABNT foi o da amostra de madeira em forma de serragem, para qual a equação obtida explica $86,1 \%$ da variação da umidade real (Tabela 2).

Tabela 1. Teste $t$ pareado para os métodos alternativos de determinação de umidade, em comparação com o método tradicional, sem e com correções.

\begin{tabular}{lccc}
\hline \multicolumn{1}{c}{ Método alternativo } & $\begin{array}{c}\text { Leitura } \\
\text { direta }\end{array}$ & $\begin{array}{c}\text { Fator de } \\
\text { correção }\end{array}$ & Regressão \\
\hline Madeira em serragem & $8,57 *$ & $2,37 \mathrm{~ns}$ & $1,43 \mathrm{~ns}$ \\
Medidor elétrico - Topo & $20,46 *$ & $3,36 *$ & $1,67 \mathrm{~ns}$ \\
Medidor elétrico - Lateral & $15,59 *$ & $3,04 *$ & $1,69 \mathrm{~ns}$ \\
\hline
\end{tabular}

* É significativamente diferente do resultado obtido quando aplicada a metodologia da ABNT; ns = não apresenta diferença significativa com os resultados obtidos quando aplicada a metodologia da ABNT.

Tabela 2. Coeficientes do modelo de regressão obtidos por cada método alternativo de determinação de umidade da madeira em tora.

\begin{tabular}{lccccc}
\hline \multicolumn{1}{c}{$\begin{array}{c}\text { Método } \\
\text { alternativo }\end{array}$} & $\mathbf{B}_{\mathbf{0}}$ & $\mathbf{B}_{\mathbf{1}}$ & $\mathbf{B}_{\mathbf{2}}$ & $\mathbf{R}^{\mathbf{2}}$ & $\mathbf{S}_{\mathbf{y} \cdot \mathbf{x}}$ \\
\hline $\begin{array}{l}\text { Madeira em } \\
\text { serragem }\end{array}$ & $-4,6002$ & 3,0492 & 0,5754 & 0,8610 & 11,4683 \\
$\mathrm{t}=$ & $-1,1431$ & 7,0944 & 7,7864 & & \\
$\begin{array}{l}\text { Medidor } \\
\text { elétrico Topo }\end{array}$ & $-17,776$ & 4,75676 & 0,93073 & 0,72014 & 16,2726 \\
$\mathrm{t}=$ & $-2,5907$ & 9,26032 & 2,10825 & & \\
$\begin{array}{l}\text { Medidor } \\
\text { elétrico Lateral }\end{array}$ & $-23,68$ & 4,04352 & 1,46139 & 0,75976 & 15,077 \\
$\mathrm{t}=$ & $-3,6529$ & 7,5489 & 3,68614 & & \\
\hline
\end{tabular}

Sendo: $\beta_{0}, \beta_{1}, \beta_{2}$ são os parâmetros do modelo; $R=$ coeficiente de determinação, Sxy $=$ erro padrão da estimativa.

A leitura direta pelos métodos alternativos não apresentou uma tendência de $45^{\circ}$ no gráfico de dispersão (Figura 1), logo os valores obtidos pela determinação do teor de umidade da madeira pelos métodos alternativos não estão coerentes com os obtidos com o método da ABNT. O método da amostra de madeira em serragem apresentou a tendência mais próxima ao método preconizado pela ABNT. Chagas (2010) e Donato et al. (2012) realizaram um estudo de comparação da umidade determinada pelo método da serragem com o método estabelecido pela norma da ABNT, para madeira de eucalipto, encontrando um padrão de resposta semelhante. 

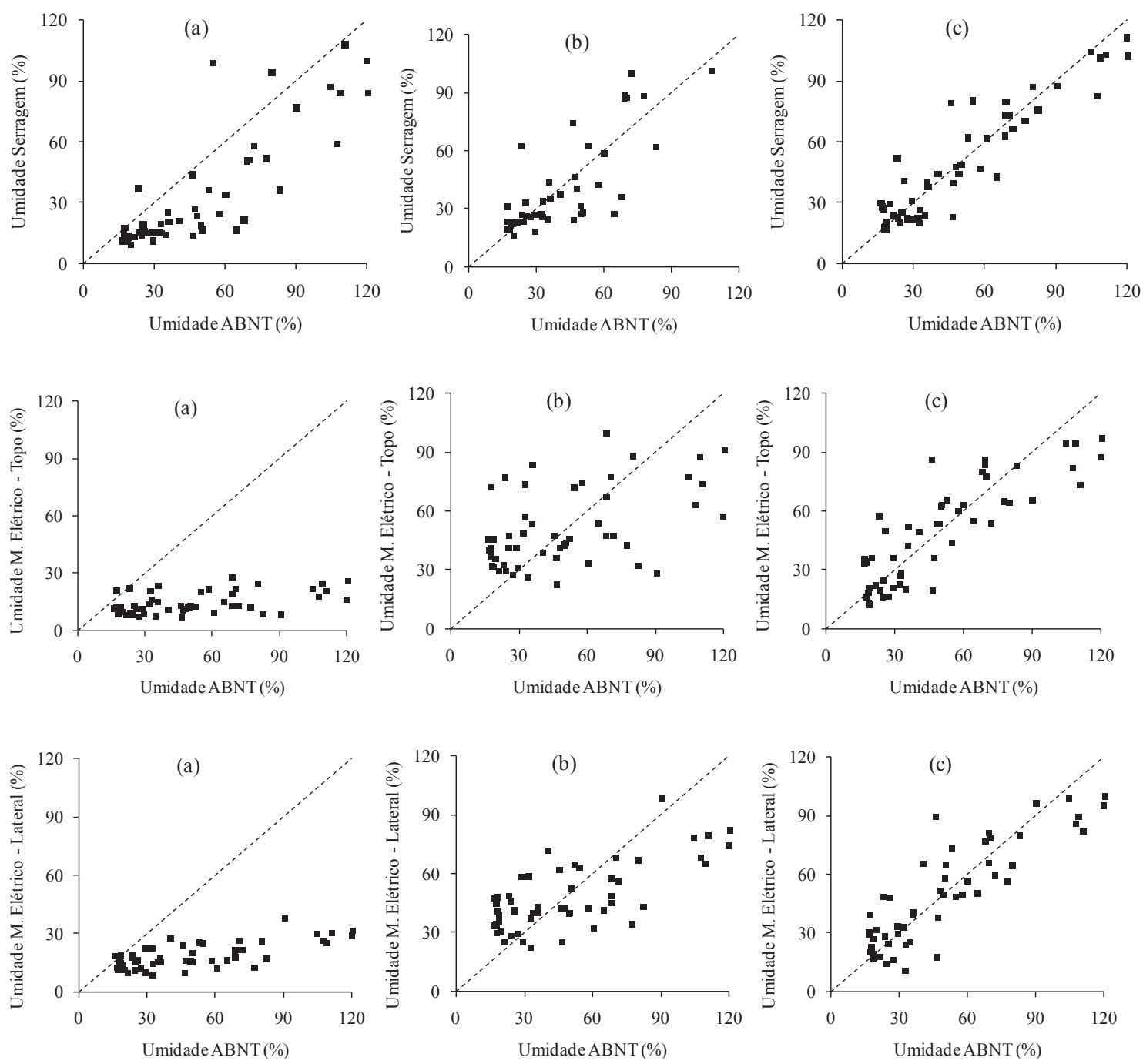

Figura 1. Dispersão dos valores de umidade obtidos pelo método tradicional (ABNT) em função de cada método alternativo, em que: (a) Leitura direta; (b) Fator de correção médio; (c) Modelo de regressão.

Não há registro na literatura de trabalhos que utilizam fatores de correção para os métodos alternativos avaliados neste trabalho, para se estimar a umidade real da madeira. Entretanto, a estimativa da umidade por estes métodos fornece valores inferiores ao método tradicional, subestimando a quantidade de água na madeira.

No caso dos medidores elétricos, segundo Moreschi (2005), suas determinações são subestimadas para teores de umidade acima do ponto de saturação das fibras (PSF). Já para determinações abaixo do PSF, de 7\% a $30 \%$ de teor de umidade, esses aparelhos têm uma maior precisão. A perda de precisão das estimativas de teor de umidade acima do PSF é explicada por Jankowsky (2000). O autor atribui o fato à presença de água livre, que apresenta resistência muito menor que a da madeira. Isto explica os desvios crescentes à medida que o teor de umidade da madeira aumenta.

De acordo com James (1988) a maioria dos medidores de umidade, quando apropriadamente utilizados, fornece uma estimativa do teor de umidade rápida e suficientemente precisa para a maioria dos casos, quando abaixo do PSF. Já Simpson (1991), ressalta que $7 \%$ é o limite inferior para que as medidas do teor de umidade sejam válidas. $\mathrm{O}$ autor afirma ainda que medidores capacitivos tenham abrangência de até 
$19 \mathrm{~mm}$ de profundidade nas leituras do campo elétrico, com influência predominante da camada externa. Uma explicação para as leituras do medidor capacitivo, predominantemente abaixo do real até $15 \%$ de umidade, é a influência maior da camada externa que durante a secagem está mais seca que a média da peça.

\section{Conclusão}

De modo geral, a leitura direta para determinar o teor de umidade da madeira pelos métodos utilizados nesse estudo não apresentaram resultados satisfatórios quando comparados com o método tradicional. Porém, com a utilização do modelo de regressão, todas as metodologias apresentaram resultados confiáveis.

A semelhança entre os valores corrigidos pelo modelo de regressão para os métodos aqui utilizados sugere que é possível desenvolver correções de métodos alternativos para se determinar a umidade da madeira em tora em substituição ao método tradicional.

\section{Agradecimentos}

Os autores agradecem à Fundação de Amparo à Pesquisa do Estado de Minas Gerais - FAPEMIG, à Secretaria de Estado, Ciência, Tecnologia e Ensino Superior - SECTES/ MG, ao Conselho Nacional de Pesquisa e Desenvolvimento - CNPq e ao Grupo de Pesquisa de Carvão Vegetal - G6 pelo apoio financeiro, em especial à empresa Gerdau Florestal S.A.

\section{Referências}

ASSOCIAÇÃO BRASILEIRA DE NORMAS TÉCNICAS. NBR 14929: madeira: determinação da umidade da madeira. Rio de Janeiro, 2003.

BARRICHELO, L. E. G.; BRITO, J. O. Correlações entre teor de lenho tardio e densidade básica para espécies do genero Pinus. Piracicaba: IPEF, 1977. (IPEF. Circular técnica, 30). Disponível em: <http://www.ipef.br/publicacoes/ctecnica/nr030.pdf $>$. Acesso em: 10 out. 2012.

BATISTA, W. R.; SANTOS, J. E. G.; SEVERO,E. T. D.; KLAR, A. E .Calibração de um equipamento TDR (reflectometria por domínio do tempo) para a determinação da umidade da madeira de Grevillea robusta (Cunn.). Revista Energia na Agricultura, Botucatu, v. 26, n. 2, p. 129-145, 2011.

CHAGAS, L. Secagem da madeira para produção de carvão vegetal. In: FÓRUM NACIONAL SOBRE CARVÃO VEGETAL, 2., 2010, Sete Lagoas. [Trabalhos...]. Sete Lagoas, 2010.
CALONEGO, F. W.; BATISTA, W. R.; SEVERO, E. T. D.; SANTOS, J. E. G. dos; RIBAS, C. Avaliação do teor de umidade da madeira de Eucalyptus grandis por medidores elétricos resistivos. Revista do Instituto Florestal, São Paulo, v. 18, n. único, p. 71-78, 2006.

DONATO, D. B.; CARDOSO, M. T.; CANDIDO W. L.; MAGALHÃES M. A.; OLIVEIRA, A. C.; CARNEIRO, A. C. O. Metodologia rápida para a determinação da umidade da madeira em tora. In: FÓRUM BRASIL SOBRE BIOMASSA E ENERGIA, 2012, Viçosa, MG. [Anais...]. Viçosa, MG: Sociedade de Investigações Florestais; UFV, 2012.

JAMES, W. L. Electric moisture meters for wood. Madison: USDA, Forest Service, Forest Products Laboratory, 1988. (Geneneral Techical Report. FPLGTR-6).

JANKOWSKY, I. P. Melhorando a eficiência dos secadores para madeira serrada. Piracicaba: IPEF, 2000. (IPEF. Circular técnica, 191).

MORESCHI, J. C. Propriedades tecnológicas da madeira: manual didático. Curitiba: Departamento de Engenharia e Tecnologia Florestal da UFPR, 2005. 168 p.

REZENDE, R. N. Secagem de toras de clones de Eucalyptus empregados na produção de carvão. 2009. 178 f. Dissertação (Mestrado em Engenharia Florestal) Universidade Federal de Lavras, Lavras.

SIMPSON, W. T. Dry kiln operator's manual. Madison: USDA. Forest Service, Forest Products Laboratory, 1991. (Agriculture Handbook, 188).

STATSOFT. Statistica: data analysis software system: version 8 . 2009. 